$\begin{gathered}\text { Revista do Departamento de Geografia } \\ \text { Universidade de São Paulo } \\ \text { www.revistas.usp.br/rdg } \\ \text { Volume Especial (2016) }\end{gathered}$
ISSN 2236-2878

\title{
ASPECTOS DO CAMPO HIGROTÉRMICO E A FORMAÇÃO DA ILHA DE CALOR URBANA NO MUNICÍPIO DE SOROCABA-SP, BRASIL
}

\section{ANALYSES OF THE TEMPERATURE AND HUMIDITY ASPECTS AND THE FORMATION OF THE URBAN HEAT ISLAND IN SOROCABA-SP, BRAZIL}

\author{
Alindomar Lacerda Silva \\ Instituto Nacional de Pesquisas Espaciais \\ alindomarlacerda10@gmail.com \\ Edelci Nunes da Silva \\ Universidade Federal de São Carlos \\ enunes@ufscar.br
}

\begin{abstract}
Many researchers have been studying urban climates. Usually they discuss the impacts of urban growth in the quality of the air, in the life of cities' inhabitants, and in the temperature. Within this context, we chose to analyze the urban climate of Sorocaba, a medium sized city that has shown a constant industrial and economic growth. There are three main goals in this paper: first is to contribute to the climatologic literature in the region; second, to provide a comparative analysis of the humidity and temperature of air in the urban and rural area; and third, to identify the signs of an urban heat island (UHI). We installed HOBBO U1O dataloggers in the central area of the city and in the rural neighborhood. We set the devices to collect data of temperature and humidity of air every one hour (24h per day), from July 4th, 2012 to July 2nd, 2013. We found that the temperature and humidity of air followed the standard trend for the region. The minimum temperatures in the urban area were higher than those temperatures in the rural neighborhood, and the relative humidity values were lower in the city center. The results point out to the existence of an urban heat island with varying magnitude, indicating that the urbanization, population, and industrial growth have already induced to local changes in the urban atmosphere.
\end{abstract}

Keywords: Urban Climate, Temperature of air, Relative humidity, Urban heat island

Palavras-chave: Clima urbano, Temperatura do ar, Umidade relativa do ar, Ilha de calor. 


\title{
INTRODUÇÃO
}

Ao longo da história o homem se mostrou transformador do espaço terrestre materializando ideias através das técnicas empregadas no trabalho. Estas transformações são de fundamental importância para a ciência geográfica na busca da compreensão dos aspectos sociais e naturais que agem sobre o espaço.

O clima sempre influenciou a vida dos seres vivos em todo o planeta. De fato a diversidade de formas de vida como se conhece só é possível graças à combinação da atmosfera, litosfera e hidrosfera que, juntas formam a biosfera. É importante lembrar que as esferas integram-se umas com as outras de forma a compor o todo do sistema - o planeta - ao mesmo tempo em que cada esfera possui subsistemas que são vitais ao todo. Em relação ao clima urbano, devem-se considerar dois fatores: um "físico" que está vinculado à dinâmica atmosférica e climatológica; e o social relativo à estrutura e a complexidade do urbano.

A atmosfera age sobre a cidade (...) tudo que não é atmosférico se concretiza no espaço urbano, incluindo o homem e demais seres vivos, constitui elementos do sistema, (...) esse conjunto complexo e estruturado (...) não é estático ou passivo (MONTEIRO 2015, p. 95).

A fim de captar essa complexidade Tarifa e Sette (2009) propõem o conceito de holorritmo, pois para os autores os elementos do espaço geográfico interagem entre si, de forma dinâmica e a interação dos fatores e dos elementos do clima influencia e desempenha um papel importante na dinâmica climática local:

\begin{abstract}
$\mathrm{Na}$ perspectiva em que os climas são tratados como flutuações físicas e/ou biológicas, as interações com os ritmos das organizações sociais e econômicas contidas no ambiente encontram-se dialeticamente contidas no espaço. Portanto, os conceitos de ritmos, produção e apropriação da natureza são uma possibilidade de melhor compreensão da totalidade das interações entre os fenômenos físicos, biológicos, sociais e econômicos (TARIFA e SETTE 2009, p. 02).
\end{abstract}

Atualmente, as cidades concentram grande parte da população mundial e estas consistem em ambientes muito diferentes do campo que já é alterado. O concreto, os prédios, as casas, os carros, os sinaleiros de trânsito, a circulação de pessoas fazem com que a cidade tenha ritmos e características próprias. Ritmos estes que geram alterações na atmosfera, pois os padrões de circulação do ar dentro da cidade, assim como a absorção e emissão de radiação são diferentes daqueles materiais que compõem a zona rural e as áreas naturais conservadas/preservadas. Na zona rural, apesar de existir uma alteração significativa do espaço, a presença de vegetação, de pastagens e a dinâmica do trabalho caracterizam ritmos diferentes daqueles do urbano.

Nas cidades modernas as indústrias trabalham a todo vapor, liberam gases para a atmosfera, além de poluir rios e solos contribuem também para a deterioração do clima e do ambiente das cidades. Primeiro estudo dedicado ao clima das cidades foi feito por Howard, em 1833, sobre o clima de Londres, o estudo menciona as diferenças de temperatura entre o campo e a área urbanizada e descreve o problema das névoas urbanas (city fog) e as repercussões adversas à saúde (LANDSBERG, 2006).

Landsberg (2006) afirma que praticamente todos os elementos climáticos são afetados pela poluição - a radiação, a nebulosidade, a visibilidade e o campo elétrico atmosférico. Num segundo estágio, a temperatura, a precipitação e a umidade relativa do ar também são influenciadas. Hoje, o clima poluído certamente é o problema básico da climatologia das cidades modernas industrializadas. (LANDSBERG, 2006, p. 96). A não consideração de fatores climáticos ao planejar uma cidade implica em problemas relacionados tanto em relação à estrutura urbana, quanto em relação à saúde dos seres vivos, "a poluição afeta de forma adversa as plantas... provoca incalculável dano por corrosão e é indubitavelmente prejudicial à saúde humana..." (LANDSBERG, 2006, p. 96).

Um dos estudos que mais contribuíram para a compreensão do clima urbano em escala mundial foi feito por Oke em 1976, quando o autor investiga as diversas camadas que compõem a atmosfera urbana: a Urban Boundary Layer - camada de ar sobre a cidade e a Urban Canopy Layer - camada que engloba os cânions urbanos. Nestas camadas ocorrem padrões diferentes de circulação do ar, especialmente nos cânions urbanos. O autor mostra que existem diferentes ilhas de calor urbanas causadas pelo ambiente citadino (OK, 1976 apud ARNFIELD 2003, p. 04). O autor ressaltava a necessidade do aumento das investigações sobre a dinâmica climática urbana em ambientes tropicais, em razão do crescimento do número de indivíduos que passariam a viver nestas áreas (OKE apud ARNFIELD, 2003 p. 01). 
No contexto nacional, um dos autores que mais contribuiu para os estudos nessa área foi o geógrafo Carlos Augusto de Figueiredo Monteiro, com sua proposta metodológica de análise dos climas urbanos, em Teoria e Clima Urbano (1976), que é amplamente utilizada nas pesquisas em nosso país, especialmente em cidades de pequeno e médio porte (MONTEIRO e MENDONÇA 2003).

LOMBARDO (1985) em estudo pioneiro mostrou a ocorrência da ilha de calor, na cidade de São Paulo, e identificou maior intensidade de temperatura com diferenças de até $10^{\circ} \mathrm{C}$, em condições sinópticas específicas, nas áreas mais densamente construídas e atenuação das temperaturas nas regiões da cidade onde há maior concentração de áreas verdes e reservatórios de água. Segundo Fialho (2012, p. 61) a ilha de calor é causada pela:

(...) expansão da mancha urbana que intensifica os fluxos intra-urbanos, além de incrementar a densidade de área construída. Essa diferenciação em relação ao campo acarreta uma diferença no tempo de absorção da energia solar disponível durante o dia, e da reemissão de energia terrestre durante a noite. A consequência deste novo balanço de energia é o resfriamento mais lento da cidade após o pôr do sol. (...) Isto nos induz a dizer que a ilha de calor está relacionada às atividades humanas sobre a superfície e sua repercussão na troposfera interior.

Algumas pesquisas mostram que nas ilhas de calor urbanas ocorre desconforto térmico e, que esse fenômeno pode ser responsável pelo agravamento de problemas respiratórios e cardiovasculares (RIBEIRO SOBRAL 2005; SILVA et al., 2015).

O clima de Sorocaba foi estudado por Tavares (1996) e sua pesquisa comparou dados de duas estações meteorológicas. Uma das considerações feitas pelo autor aponta que as diferenças de temperatura do ar entre a cidade e o campo são possivelmente provocadas pela mudança de tempo e não produzidas pelo mecanismo urbano. (TAVARES 1996, p. 177).

No entanto, com as intensas transformações ocorridas em Sorocaba nas últimas décadas - uma cidade média do interior paulista distante cerca de $100 \mathrm{~km}$ da capital, com aproximadamente 600.000 habitantes (IBGE 2014) e a ampliação de sua malha urbana - percebeu-se a necessidade de investigar o comportamento da temperatura e umidade relativa do ar e identificar a ocorrência do fenômeno da ilha de calor. Sendo assim, suspeitou-se que o tamanho da mancha urbana do município seria capaz de produzir transformações na atmosfera local a ponto de fazer o centro urbano mais quente que o entorno rural. Considerou então que, a intensidade dos padrões de ocupação do solo, as condições geoecológicas do sitio urbano podem ampliar e intensificar o fenômeno da ilha de calor. Este artigo tem como objetivo fazer uma análise comparativa da temperatura e a umidade relativa do ar na zona rural e urbana e identificar a formação e intensidade da ilha de calor urbana, no município de Sorocaba-SP.

\section{MATERIAIS E MÉTODOS}

A pesquisa foi embasada na proposta teórica elaborada por Monteiro (2003), que trata de uma abordagem rítmica e o Sistema Clima Urbano (SCU), numa escala local. O canal da percepção em questão é o Conforto Térmico que por sua vez faz parte do subsistema termodinâmico (MONTEIRO, 2003).

Essa abordagem pelo SCU permite compreender os múltiplos agentes que operam na produção do clima urbano. De acordo com Monteiro, tudo o que não é atmosférico e que se concretiza no espaço urbano, incluindo o homem e demais seres vivos, constitui elementos do sistema, estruturando-se em partes que, através de suas reações, definem atributos especiais. Assim, esse conjunto complexo e estruturado constitui o operando do sistema. Pela sua natureza, é um tipo especial de operando, que não é estático ou passivo (MONTEIRO 2003, p. 21).

Uma particularidade do SCU é a articulação entre escalas - do microclima ao clima zonal. Considera que a cidade se insere na escala local do clima, que por sua vez está interligada a escalas maiores, como a sub-regional, regional e zonal; ao mesmo passo em que dentro da cidade existem escalas menores, como o mesoclima, topoclima e microclima (MONTEIRO, 2003, p. 28). Dessa forma, esta pesquisa foi realizada na escala local cujo centro urbano de Sorocaba consistiu no operando do sistema e o entorno rural como parâmetro de controle. Deste modo pudemos compará-los e verificar se o campo higrotérmico se encontra alterado devido às influencias dos elementos do sistema urbano no nível local. Para isso a pesquisa se estruturou conforme descrito nos passos a seguir. 


\section{Pesquisa de Campo}

Foram selecionados dois pontos distintos de amostragem e distantes entre si cerca de $20 \mathrm{~km}$. O primeiro deles está situado no centro da cidade de Sorocaba numa área bem adensada com relação à quantidade de prédios, casas, fluxo de carros e de pessoas. O segundo ponto fica em uma fazenda, com campos para pastagem de cavalos, com muitas árvores e uma paisagem típica de áreas rurais (Figura 1).

Considerando, portanto, os locais que melhor representam as características urbanas e rurais. Ambos os aparelhos foram instalados no meio da vertente dos respectivos espigões e voltados para a face sul (Figura 2). O ponto de amostragem na zona urbana foi colocado na escola XXXX, cuja altitude média de $560 \mathrm{~m}$, próximo do vale do Rio Sorocaba, que corta a cidade. O ponto da zona rural está localizado na Fazenda Malagueta, situada na Estrada Bom Jardim, Bairro Mato Dentro, no município de Mairinque divisa com Sorocaba cuja altitude é de $620 \mathrm{~m}$.

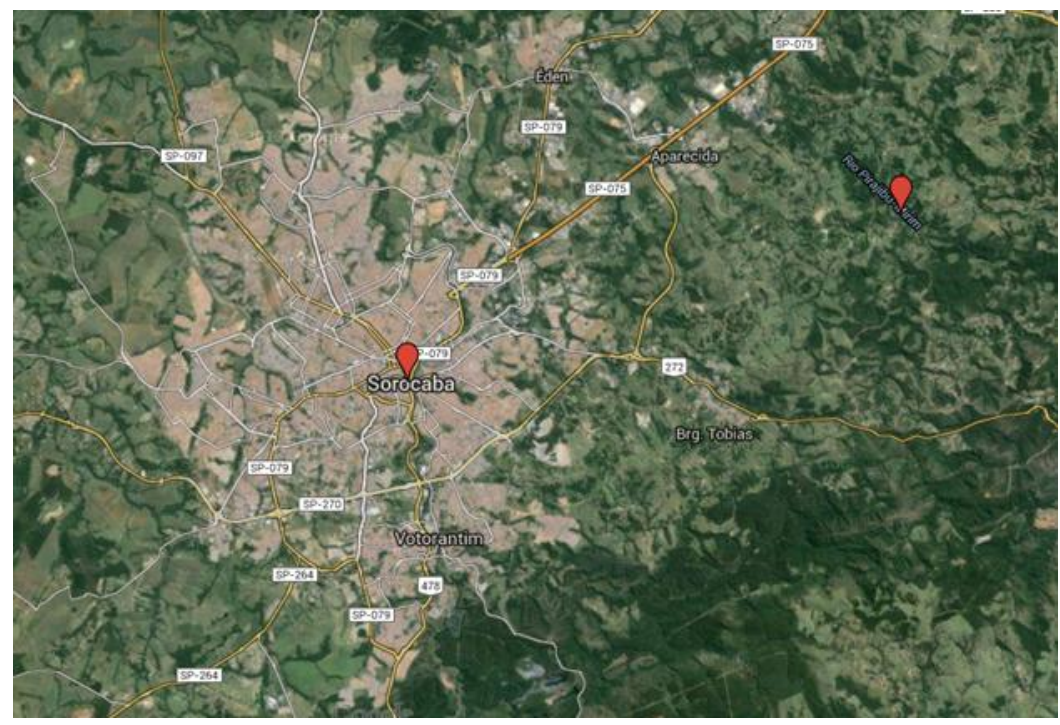

Figura 1: Localização dos pontos de amostragem urbano e rural, Sorocaba, SP. Fonte: Google Maps/Satellite (2015). Adaptado.

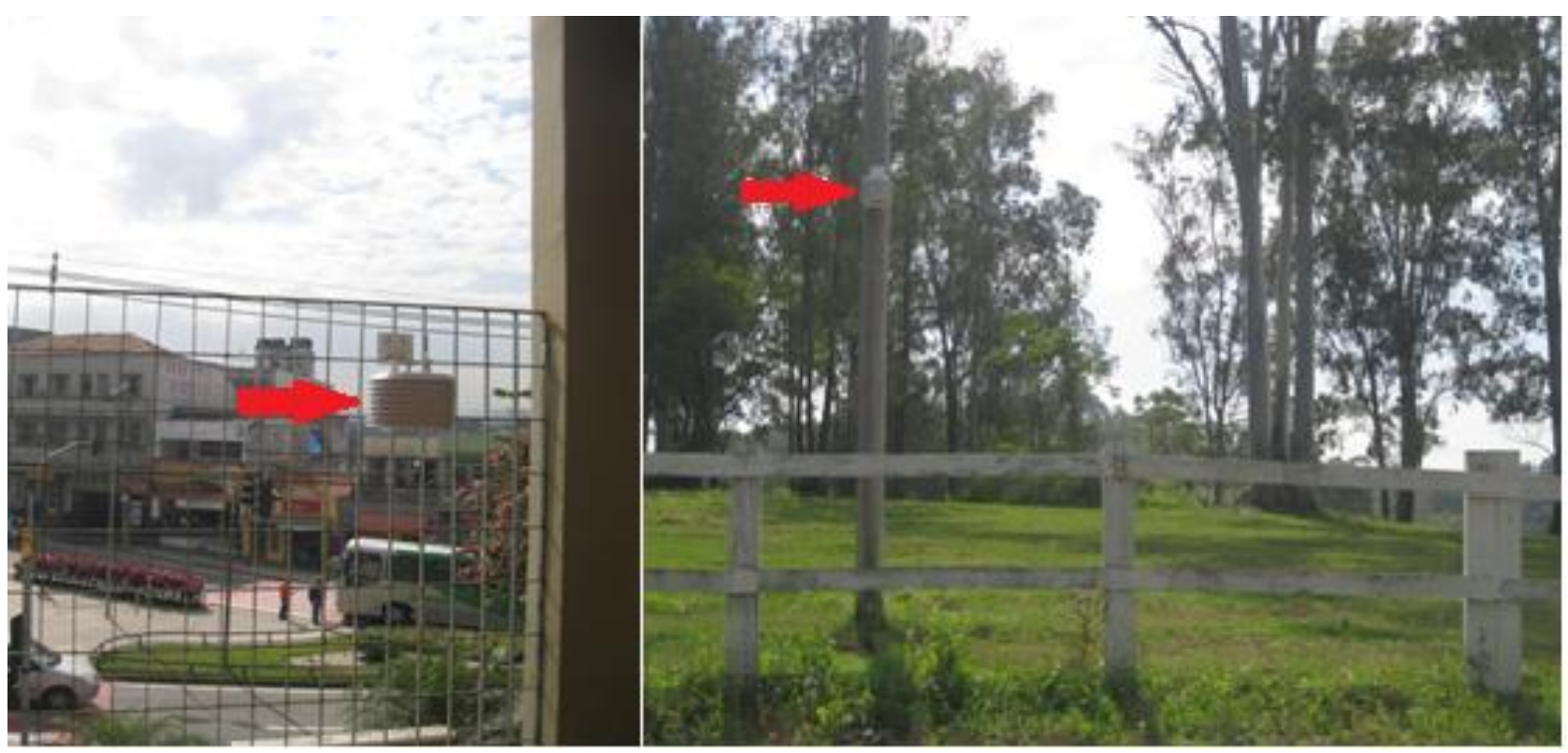

Figura 2: Localização dos pontos de amostragem urbano e rural, Sorocaba, SP. Foto: Alindomar Lacerda Silva. 


\section{Características dos aparelhos}

Foram utilizados datalogger Modelo HOBO U10 Temp./RH e abrigos passivo indicado para impedir a incidência de radiação solar direta. Os registradores foram programados para coletar os dados de temperatura e umidade relativa do ar $24 \mathrm{~h}$ por dia, no intervalo de $1 \mathrm{~h}$ em $1 \mathrm{~h}$ no período de Julho de 2012 a Julho de 2013. Os aparelhos foram calibrados entre si e foi feita a correlação dos dados.

\section{Análise dos Dados}

Foram feitas a análise descritiva dos dados e a elaboração de gráficos e tabelas da série temporal para as temperaturas do ar mínima e máxima; e umidade relativa do ar da zona urbana e da zona rural. Para a variável temperatura do ar foram calculadas as diferenças $\mathrm{Tu}-\mathrm{Tr}$, onde $\mathrm{Tu}=$ temperatura do ar na zona urbana e $\mathrm{Tr}=$ temperatura do ar na zona rural. Os valores das diferenças acima de $3^{\circ} \mathrm{C}$ foram considerados como ilha de calor e estão mostrados nos gráficos.

\section{RESULTADOS E DISCUSSÃO}

O comportamento anual das temperaturas máximas e mínimas durante o período estudado seguiu o padrão do tipo climático da região de Sorocaba, ou seja, temperaturas elevadas no período de verão e mais baixas no inverno, forte oscilação e maior amplitude térmica nas estações de transição - primavera e outono. A Figura 3 mostra o comportamento dos dados de temperatura do ar mínima e máxima na zona urbana e rural do município de Sorocaba. As temperaturas máximas oscilaram entre $15^{\circ} \mathrm{C}$ e acima de $35^{\circ} \mathrm{C}$ e as temperaturas mínimas entre $3^{\circ} \mathrm{C}$ e $25^{\circ} \mathrm{C}$. Observa-se que, os valores das temperaturas do ar máximas ficaram muito próximos nos dois ambientes, na maior parte do tempo. Em alguns dias, principalmente, no período do outono/inverno as temperaturas do ar máximas da área urbana foram mais elevadas em relação à área rural.

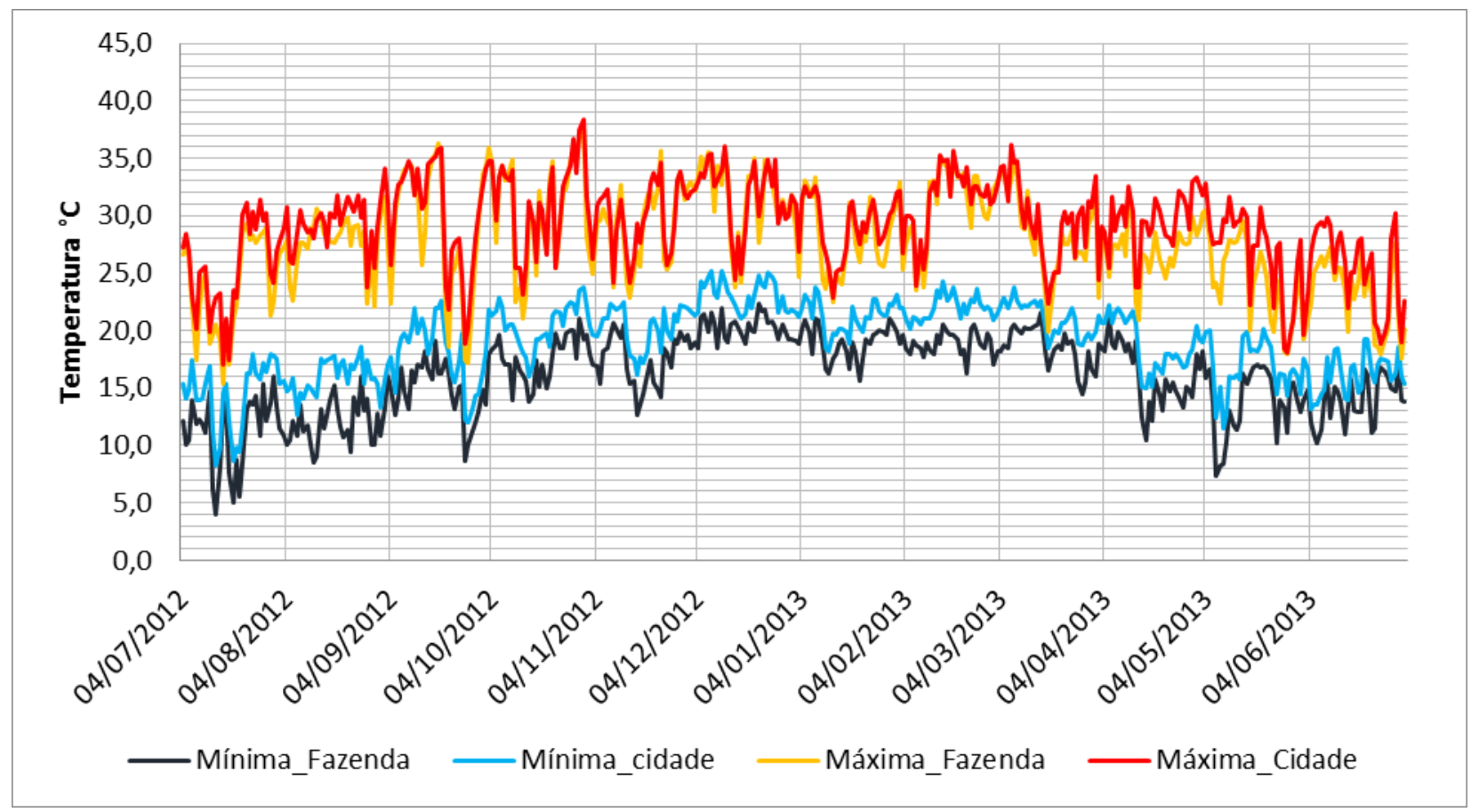

Figura 3: Evolução diária das temperaturas mínima e máxima do ar na zona urbana e na zona rural, no período de 04/07/2012 a 02/07/2013, no município de Sorocaba-SP. Elaborado por Alindomar Lacerda Silva, 2015. 
As temperaturas do ar mínimas da área urbana foram mais elevadas do que às da área rural na maior parte dos dias. As diferenças entre as temperaturas do ar mínimas da área urbana e as temperaturas do ar mínimas da área rural são nítidas sendo que, na área urbana, elas ficaram mais elevadas do que na área rural. Esse comportamento das temperaturas do ar mínimas vem sendo observado em vários outros estudos que comparam dados de temperatura do ar em áreas urbanas e áreas não urbanas (CABRAL, 1998; RIBEIRO e AZEVEDO, 2003; DONATO et al. 2008; SILVA, 2010)

A Figura 4 mostra os dados diários da umidade relativa do ar, no período de 04 de julho de 2012 a 02 de julho de 2013. A umidade relativa do ar é mais elevada na área rural, com valores máximos entre $80 \%$ e 100\%, enquanto na área urbana os valores de umidade relativa do ar máximos são mais baixos e oscilaram entre $60 \%$ e $100 \%$. Observa-se, porém que os valores de $100 \%$ de umidade relativa do ar, na área urbana, foram mais raros. Os valores mínimos da umidade relativa do ar foram, na maior parte do tempo, mais elevados na área rural em relação à área urbana. Tanto na área rural quanto na área urbana os valores mínimos, em alguns dias, ultrapassaram $80 \%$, no entanto, a área urbana esses valores mínimos foram mais raros. Nota-se que na área urbana os valores mínimos de umidade relativa do ar são, frequentemente, inferiores aos da área rural.

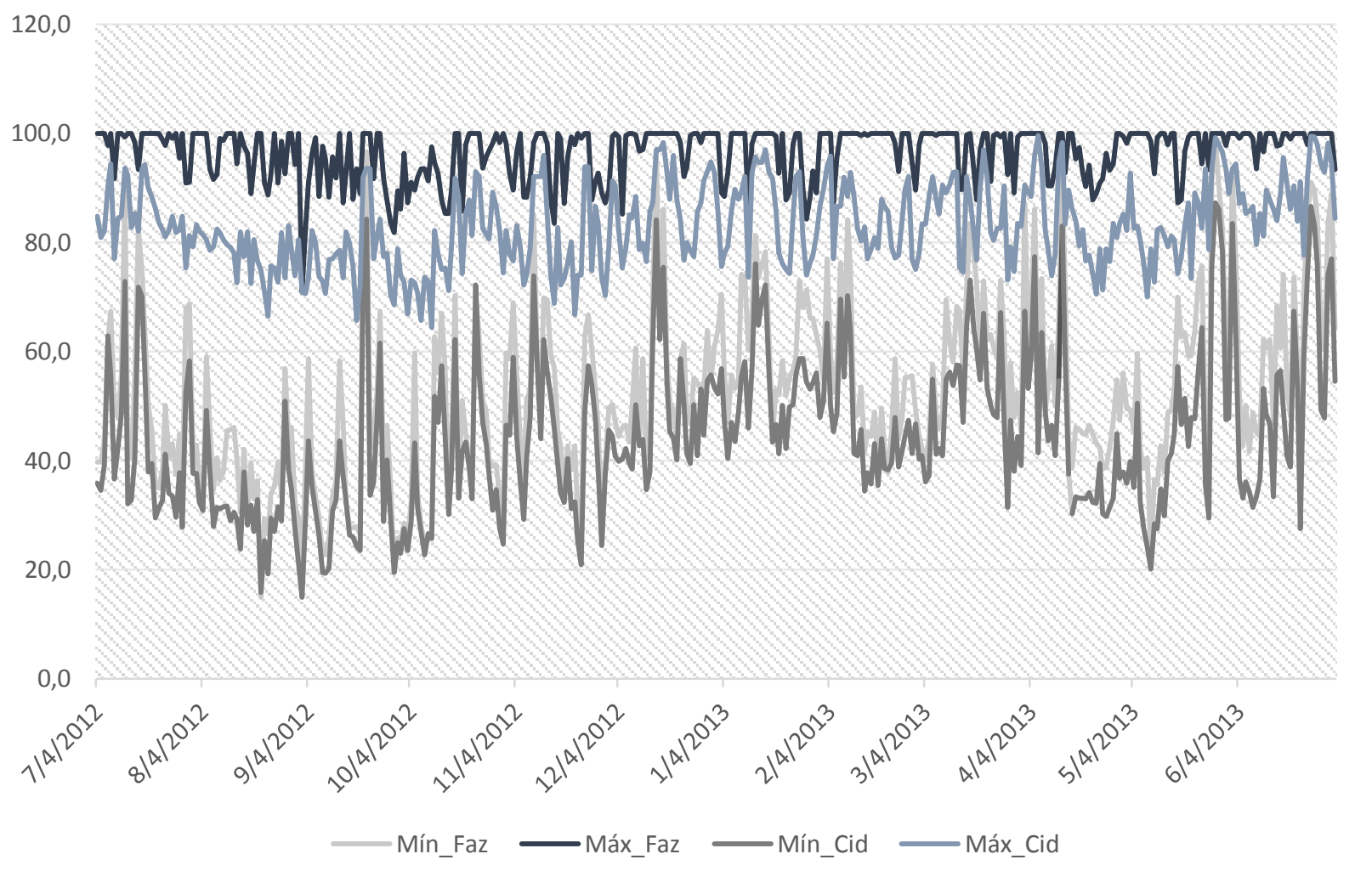

Figura 4: Evolução diária das umidades relativa do ar zona urbana e na zona rural, no período de 04/07/2012 a 02/07/2013, no município de Sorocaba-SP. Elaborado por Alindomar Lacerda Silva, 2015.

Com relação à umidade relativa do ar os meses de julho, agosto, e setembro foram os mais secos. Fevereiro de 2013 também foi um mês seco, bem como os meses do outono de 2013, que apresentaram valores bem baixos de umidade relativa do ar. Observa-se que, quando a umidade relativa do ar estava baixa, as maiores intensidades da ilha de calor foram observadas, mostrando que em regiões tropicais as diferenças entre estação do ano são determinantes na formação de ilha de calor.

No que tange as diferenças entre zona urbana e rural da umidade relativa do ar, a zona urbana apresenta menores valores de umidade. Esse fato foi verificado também por Kuttler et al. (2007) em um estudo para a cidade de Krefeld, Alemanha; utilizando uma metodologia de comparação similar a usada neste trabalho. $\mathrm{O}$ autor afirma que: áreas urbanas geralmente são caracterizadas por apresentarem valores de umidade mais baixos quando comparadas aos ambientes de entorno não construídos (KUTLER et al. 2007, p. 2005). 
Em Sorocaba, os meses mais secos do ano também foram os de inverno, tanto na zona urbana quanto na zona rural, como esperado para o tipo climático da região. Em alguns momentos, a umidade relativa do ar chegou a ficar abaixo dos $20 \%$, o que está muito longe do recomendável pela $\mathrm{OMS}^{1}$ para manutenção da saúde e do conforto térmico humano.

Há uma escassez de estudos que analisam a umidade relativa do ar em áreas urbanas, como constatado em Jáuregui e Tejeda (1997) em um estudo para a Cidade do México:

Dentre os diversos parâmetros climáticos que vem sendo objeto de estudo do ambiente urbano, umidade vem recebendo pouca atenção. A escassez de pesquisas sobre a umidade urbana vem sendo observada por Chandler (1967), Landsberg (1981), e Ackerman (1987). Essa situação se deve ao fato de que as diferenças de umidade entre o urbano-rural sejam pequenas e a distribuição espacial correspondente é geralmente complexa, como notou Chandler (1967). Além do que, as relações entre a fábrica urbana e o padrão da pressão do vapor são difíceis de explicar." (JÁUREGUI e TEJEDA, 1997, p. 187).

Este trabalho indicou que os valores diários da umidade relativa do ar são frequentemente mais baixos na área urbana quando comparados com a área rural em qualquer época do ano. A Figura 5 apresenta a diferença de temperatura do ar entre a área urbana e a área rural no período estudado.

A intensidade da diferença de temperaturas do ar entre a zona rural e a zona urbana acima de $3^{\circ} \mathrm{C}$ foi considerada para a existência ilha de calor. Algumas características são ressaltadas: A ocorrência da ilha de calor nos meses de outono/inverno com maior frequência e intensidade, iniciando no final da tarde, por toda a noite e estendendo-se até às $9 \mathrm{~h}$ da manhã; os meses de primavera e verão apresentam menor frequência e intensidade de diferença de temperatura entre a zona urbana e rural acima de $3^{\circ} \mathrm{C}$; no período do diurno as temperaturas nos dois ambientes praticamente se igualam dissipando a ilha de calor.

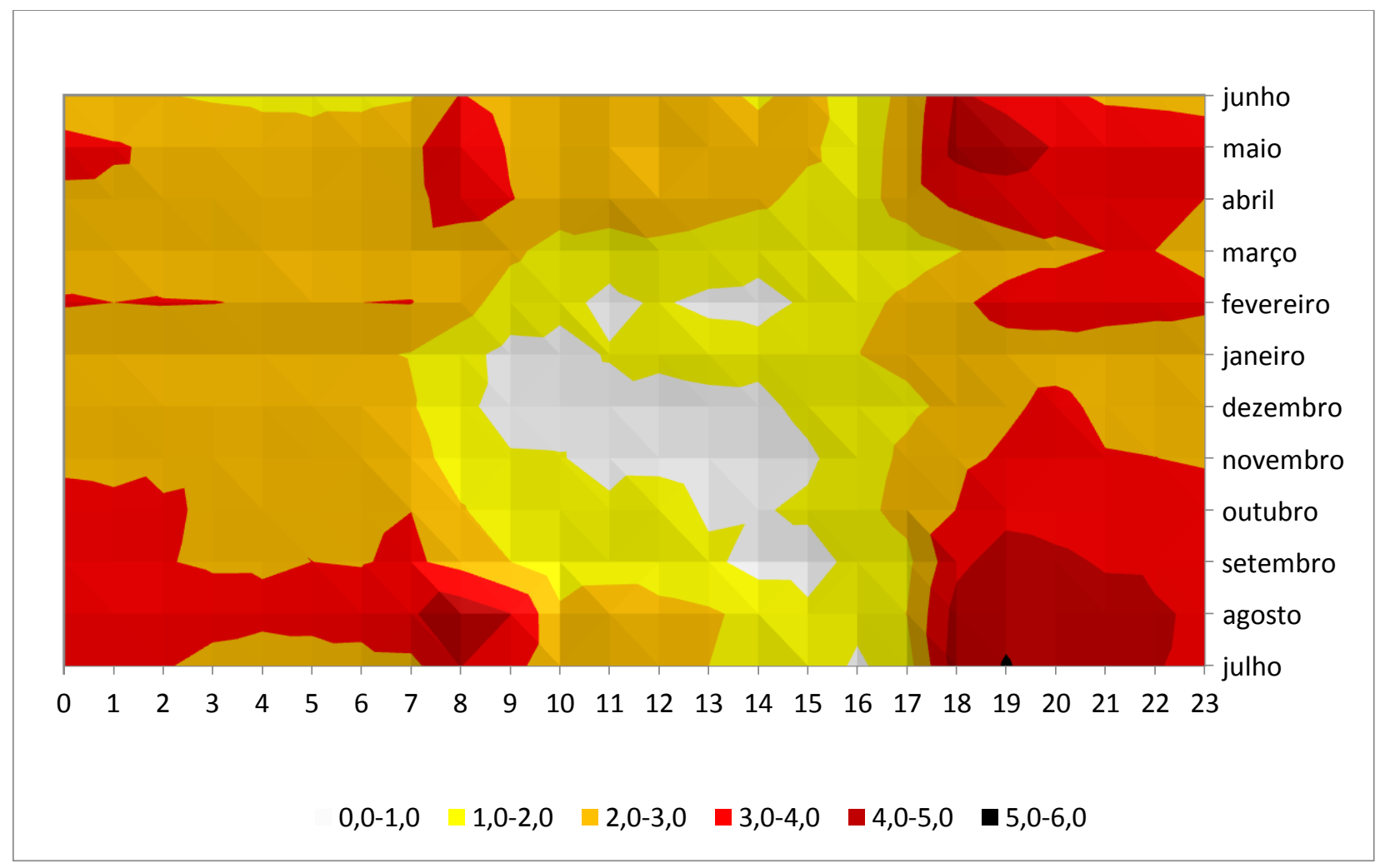

Figura 5: Diferença da média horária das temperaturas ar entre a zona urbana e na zona rural, no período de 04/07/2012 a 02/07/2013, no município de Sorocaba-SP. Elaborado por Alindomar Lacerda Silva, 2015.

\footnotetext{
${ }^{1}$ OMS (Organização Mundial da Saúde). A OMS aponta que os valores abaixo de $60 \%$ não são adequados à saúde humana.
} 
Nos meses de primavera (2012) ela perde intensidade, mas continua com valores acima $\operatorname{dos} 3^{\circ} \mathrm{C}$, nos meses de verão (2012/2013) somente em Janeiro ela não aparece, mas as médias das diferenças de temperatura são sempre maiores que $0^{\circ} \mathrm{C}$. No outono de 2013 a ilha de calor volta a ganhar intensidade, com valores acima dos $4^{\circ} \mathrm{C}$ logo após o pôr-do-sol e pouco antes do nascer do sol. Essa característica permanece até o fim do mês de junho. A Figura 6 mostra a frequência mensal das diferenças entre as temperaturas da área urbana e área rural.

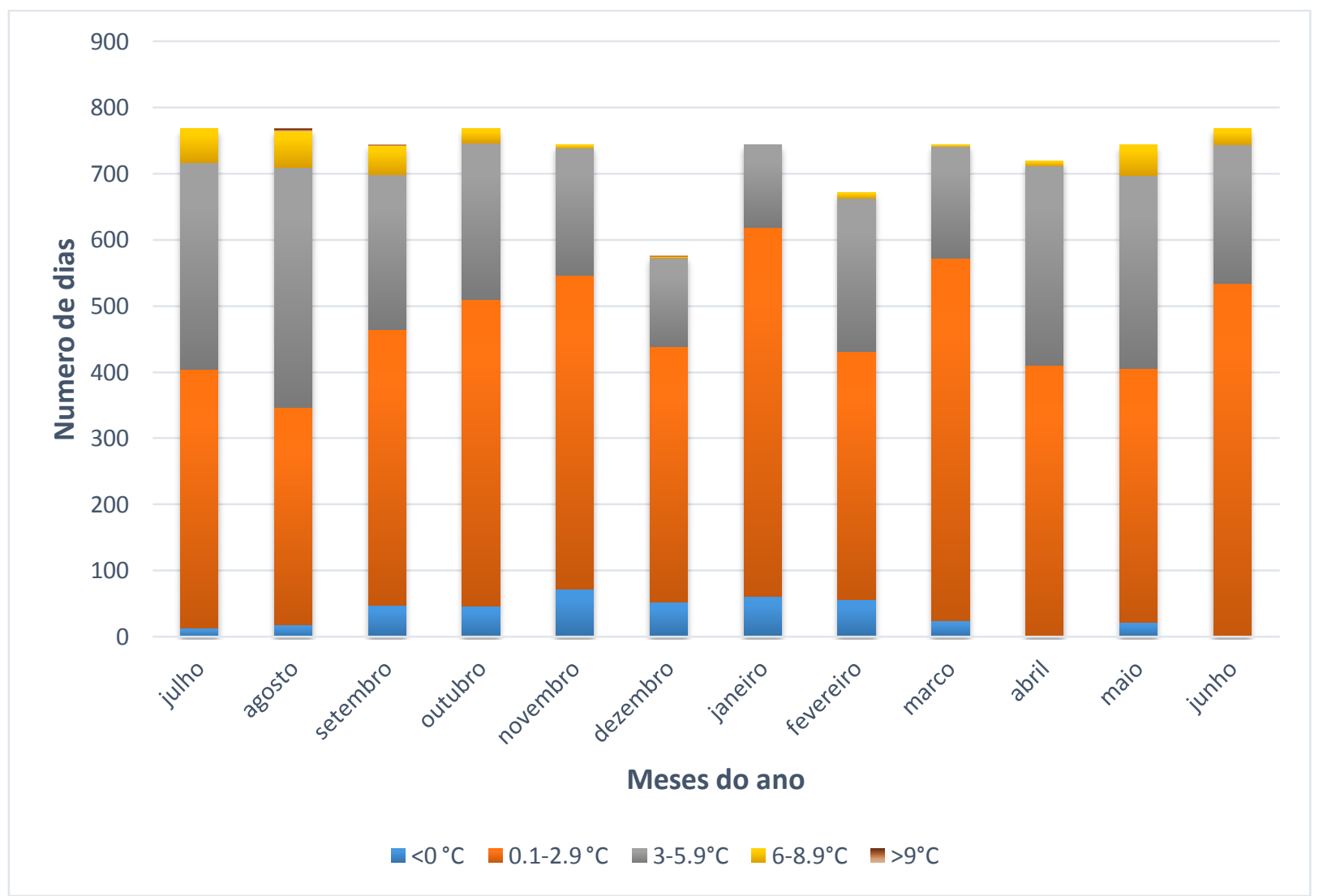

Figura 6: Frequência absoluta e intensidade da diferença da média horária das temperaturas ar entre a zona urbana e a zona rural, no período de 04/07/2012 a 02/07/2013, no município de Sorocaba-SP. Elaborado por Alindomar Lacerda Silva, 2015.

Observa-se que os meses de julho a outubro de 2012 e, os meses de abril a junho de 2013 apresentaram maior frequência de diferenças com valores de $3^{\circ} \mathrm{C}$ ou mais, correspondendo ao período de inverno/primavera/outono. Os meses de novembro/dezembro de 2012 e janeiro/março de 2013 apresentaram as menores frequências de diferença acima de $3^{\circ} \mathrm{C}$. Valores acima de $9^{\circ} \mathrm{C}$ foram mais raros e aparecem nos meses de agosto e setembro de 2012. Nota-se que nos meses entre setembro/2012 e fevereiro de 2013 há aumento das frequências de diferenças negativas, ou seja, a área rural é mais quente do que a área urbana, indicando o surgimento da ilha de frio na área urbana.

As diferenças de temperatura do ar entre as duas áreas - rural e urbana - foram observadas durante o ano inteiro. $\mathrm{O}$ que mudou foi à intensidade e frequência das diferenças de temperatura do ar entre a zona urbana e a zona rural. Valores de intensidade acima dos $3^{\circ} \mathrm{C}$ aconteceram com maior frequência nos meses do inverno de 2012 e outono de 2013, nessa época do ano há grande influência das altas pressões atmosféricas. Quando as altas pressões atmosféricas dominam na região não permitem a formação de nuvens e, consequentemente toda a radiação recebida durante o dia é liberada à noite.

A zona rural está cercada por uma área de pastagem e florestas e a zona urbana caracteriza-se pelos prédios e concreto, portanto as duas áreas têm taxas de perda radiativas diferentes, o que explica a zona urbana estar mais quente após o pôr-do-sol. Além disso, o ritmo da cidade com intenso tráfego de veículos pela manhã quando a cidade "acorda" e também no fim do dia quando as pessoas retornam do trabalho, aliado ao aumento do fluxo de pessoas no centro da cidade podem explicar as diferenças positivas das temperaturas do ar entre a cidade e o campo. 
Em estudo de um episódio de inverno na cidade de Sorocaba; Silva e Silva (2012) identificaram que, sob a atuação da frente fria as diferenças de temperatura do ar entre o rural e urbano são pequenas. Quando a frente move-se e a alta polar domina, a diferença da temperatura varia entre $3^{\circ} \mathrm{C}$ e $8,5^{\circ} \mathrm{C}$ caracterizando a formação da ilha de calor urbana.

Alves e Specian (2009, p. 190) estudaram a ilha de calor da cidade de Iporá, GO, os autores mostram que, no mês de julho quando há atuação da massa de ar seca, as ilhas de calor e as ilhas secas são mais intensas. Os autores explicam que o céu claro e a baixa velocidade dos ventos típicos desse sistema atmosférico faz com que haja maior entrada de radiação e pouco transporte dessa energia.

Coltri et al. (2007, p. 5152) afirmam que em cidades médias as estações do ano não influenciam de maneira marcante, pois as condições do entorno da cidade podem influenciar diretamente o microclima local, e que, nos grandes centros urbanos as ilhas de calor são mais intensas no verão. Contrariamente a esses achados, a presente pesquisa mostrou que as estações do ano possuem grande influência na intensidade da IC, especialmente no outono e inverno e, no verão, as intensidades das diferenças entre as temperaturas são menores e menos frequentes.

As diferenças entre as temperaturas na zona rural e urbana são causadas pelos diferentes fluxos radiativos entre as zonas durante o período noturno. Bridgman e Oliver (2006 p. 220) afirmam que na Cidade do México, por exemplo,

o calor armazenado na zona urbana supera o déficit radiativo que ocorre após o pôr-do-sol, e geralmente é a única fonte de calor durante a noite [...] deste modo uma fluxo de calor fraco se mantém a noite e que diferenças maiores de $7^{\circ} \mathrm{C}$ ocorrem somente durante as condições de tempo calmo e limpo da estação seca.

Amorim (2005 p. 127) analisando as condições sinópticas da formação das ilhas de calor do município de Birigui-SP, no mês de dezembro, mostra que, sob condições de calmaria e baixa nebulosidade tanto a magnitude da ilha de calor quanto a amplitude térmica são elevadas. No caso de Sorocaba, as maiores diferenças de temperatura do ar entre o urbano e o rural, ocorreram nos meses de inverno e não nos meses de verão, indicando que, apesar da similaridade climática, as cidades têm suas características próprias.

Os resultados aqui apresentados apontaram um padrão da ilha de calor para a cidade de Sorocaba, com dois picos ao longo do dia, um logo após o pôr-do-sol e outro antes do nascer do sol. A formação de ilha de calor nos meses de inverno pode estar associada à maior atuação da circulação anticiclônica caracterizada pelo céu claro e ventos calmos.

Em pesquisa realizada para Piracicaba, SP Coltri et al. (2007, p. 5155) observaram que a ilha de calor nos meses de inverno não possuía um padrão definido, o que reforça a ideia de que para cada cidade há uma dinâmica própria e específica.

Jonsson (2004, p. 1320) estudou a variação sazonal da ilha de calor urbana na cidade de Gaborone, Botswana; e mostrou que existe uma variação sazonal, sendo os meses secos do inverno - de junho a setembro - aqueles com as maiores intensidades das diferenças de temperatura do ar. Esse padrão também foi observado, na cidade de Sorocaba, ou seja, nos meses de inverno ocorreram as maiores intensidades de diferença das temperaturas do ar entre o rural e o urbano.

Em um estudo para Buenos Aires, Figuerola e Mazzeo (1998, p. 1712) identificaram durante o inverno que, a intensidade da ilha de calor foi de $4,6^{\circ} \mathrm{C}$. A formação se dá do por do sol até uma hora após o nascer do sol, salvo no inverno que se estende até às $8 \mathrm{~h}$ da manhã. Em Sorocaba, um dos picos da ilha de calor é justamente às $8 \mathrm{~h}$ da manhã, especialmente no inverno.

Outros resultados também foram muito parecidos com aqueles encontrados nesta pesquisa, como por exemplo: As diferenças negativas de temperatura entre a zona rural e urbana- a ilha de calor negativa DTu$\mathrm{r}(\max$, neg), ocorrem durante as horas do dia. No inverno, Dtu-r(max,neg) ocorreu entre $9 \mathrm{~h}$ e $21 \mathrm{~h}$, com um pico de frequência as $15 \mathrm{~h}$. Por outro lado, no verão, DTu-r(max, neg) ocorreu entre $8 \mathrm{~h}$ e $20 \mathrm{~h}$ com um pico as 19h (...) A maior intensidade da ilha de calor negativa ocorreu mais no verão que no inverno (FIGUEROLA e MAZZEO 1998, p. 1712), ou seja essas características também foram observadas em Sorocaba.

Chow e Roth (2006 p. 2243) em sua pesquisa para a cidade Cingapura observaram a ocorrência da ilha de calor urbana logo após o por do sol na área comercial e outros locais urbanos. Os autores afirmam que a temperatura do ar decai entre o entardecer e o anoitecer com as áreas urbanas se resfriando em taxas mais baixas que as áreas rurais e que essas características gerais da ilha de calor urbana acontecem durante 
condições de tempo calmas e de céu limpo quando as maiores magnitudes (ICUmax) são observadas (CHOW e ROTH 2006, p. 2243).

Em Sorocaba, os meses secos de julho, agosto e setembro registraram intensidades acima de $4^{\circ} \mathrm{C}$ e os de verão intensidades da diferença menores que $3^{\circ} \mathrm{C}$. Os meses de transição, por sua vez, apresentaram valores de intensidade variáveis, geralmente acima dos $3{ }^{\circ} \mathrm{C}$. Após esta análise, entende-se que há a formação de ilha de calor em Sorocaba, e que esta possui uma característica particular, relacionada à resposta do organismo urbano frente à dinâmica atmosférica sazonal. Em Sorocaba, a ilha de calor apresentou uma sazonalidade e temporalidade similar àquelas identificadas por Jonsson (2004) em Goborone; Chow e Roth (2006) em Singapura; Figuerola e Mazzeo (1998) em Buenos Aires; Bridgman e Oliver (2006). Entretanto, a ilha de calor em Sorocaba difere daquelas encontradas por Amorim (2005) em Birigui e por Coltri et al. (2007) em Piracicaba.

\section{CONCLUSÕES}

Este trabalho buscou entender o comportamento do campo higrotérmico da cidade de Sorocaba e seu entorno rural através da comparação de dois pontos distintos entre si: um na zona rural e o outro na zona urbana a fim de compreender o comportamento dos diferentes tipos de ocupação do solo frente à dinâmica climática local. Com relação à sazonalidade, as variáveis temperatura e umidade relativa do ar se comportaram da seguinte maneira:

a) No inverno as temperaturas do ar foram mais baixas principalmente nas horas da manhã e nas horas noturnas, principalmente na zona rural. A umidade relativa do ar ficou baixa nos meses de inverno, com valores atingindo os $30 \%$ em ambas as localidades: zona rural e urbana.

b) Na primavera observou-se que as temperaturas em ambas as localidades aumentam, a zona rural apresentou mínimas médias de $15^{\circ} \mathrm{C}$ e máximas de $30^{\circ} \mathrm{C}$; a zona urbana se mostrou mais aquecida. A umidade relativa do ar foi muito baixa logo nos primeiros meses de primavera, mas voltou a aumentar em novembro;

c) No verão as temperaturas do ar mínimas aumentam em ambas as localidades, a zona rural passou a apresentar valores mínimos de $17^{\circ} \mathrm{C}$, enquanto que a zona urbana registrou $20^{\circ} \mathrm{C}$; as máximas ficaram em torno de $30^{\circ} \mathrm{C}$, atingindo $32^{\circ} \mathrm{C}$ em momentos. A umidade relativa do ar apresentou valores altos entre dezembro e janeiro, mas diminuiu em fevereiro.

d) No outono, as temperaturas voltaram a diminuir, as mínimas para a zona rural ficaram em torno de $14^{\circ} \mathrm{C}$, e na zona urbana de $16^{\circ} \mathrm{C}$; já as máximas também voltam a diminuir: ficam por volta dos $26^{\circ} \mathrm{C}$ na zona rural e $28^{\circ} \mathrm{C}$ na zona urbana. A umidade relativa do ar voltou a diminuir, especialmente nos meses de abril e maio.

A análise das diferenças de temperatura do ar entre o meio urbano e rural apontam para a existência da ilha de calor na região central da cidade; indicando que a crescente urbanização, o aumento da população e o crescimento industrial de Sorocaba já impõem uma alteração na atmosfera urbana local e que, a dinâmica atmosférica, os fluxos e os ritmos urbanos influenciam a formação da ilha de calor.

Os diferentes usos do solo urbano, como praças, parques, lagos, áreas abertas e industriais interrompem a uniformidade do platô da ilha de calor, que tende a aumentar da periferia urbana em direção ao centro (Oke apud Ribeiro e Azevedo 2003, pg. 24-25). Os autores apontam que é importante analisar esses diferentes usos do solo e entender as respostas que esses ambientes dão frente à dinâmica climática.

Deve-se, portanto, considerar que esta pesquisa apontou as diferenças existentes entre um ponto central da cidade de Sorocaba e um ponto da área rural. Não se pode generalizar uma ilha de calor para toda a área urbana de Sorocaba. Para tal afirmação, seriam necessários mais pontos de coleta, a fim de identificar as características particulares dos espaços intra-urbanos e suas características.

\section{REFERENCIAS}

ALVES, E. D. L.; SPECIAN, V. Contribuição aos Estudos do Clima Urbano: variação térmica e higrométrica em espaços intra-urbanos. Mercator, Fortaleza, v. 8, n. 17 p. 181-191, set./dez. 2009.

AMORIM, M. C. C. T. Intensidade e forma da ilha de calor urbana em Presidente Prudente/SP: episódios de inverno. Geosul, Florianópolis, v. 20, n. 39 p. 65-82, jan./jun. 2005. 
ARNFIELD, A. J. Two decades of Urban Climate Research: A review of Turbulence, Exchange of Energy and Water, and the Urban Heat Island. Int. J. Climatol, v. 23, n. 1, p. 1-26, jan. 2003.

BRIDGMAN, H. A.; OLIVER, J. E. The global climate system: patterns, processes, and teleconnections. Cambridge University Press, 2006. The Edinburgh Building, Cambridge CB2 2RU, UK, 350 pgs.

CABRAL, E. Tendências térmicas urbanas no município de São Paulo (1887-1995). In III Simpósio Brasileiro de Climatologia Geográfica, 1998, Salvador. Anais... Salvador: UFBA, 1998, Anais em CD ROM, 1998.

CHOW, W. T. L.; ROTH, M. Temporal Dynamics of the Urban Heat Island in Singapore. International Journal of Climatology, v.26, n. 15, p. 2243-2260, jul. 2006.

COLTRI, P. P. et al. Ilhas de Calor da estação de inverno da área urbana do município de Piracicaba, SP. XIII Simpósio Brasileiro de Sensoriamento Remoto, 2007, Florianópolis, Anais..., Florianópolis: INPE, 2007, p. 5151-5157.

DONATO, E.K. et al. Airport and city-centre temperatures in the evaluation of the association between heat and mortality. Int J Biometeorol, v. 52, n.4, p.301-310, mar. 2008.

FIALHO, E. S. Refletindo sobre o conceito de ilha de calor. ACTA Geográfica, Boa Vista, Ed. Esp. Climatologia Geográfica, p.61-76, 2012.

FIGUEROLA, P. I.; MAZZEO, N. A. Urban-rural temperatures diferences in Buenos Aires. International Journal of Climatology, v.18, p. 1709-1723, 1998.

IBGE. Informações sobre os municípios. Diretoria de Pesquisas, Coordenação de População e Indicadores Sociais. Estimativas da população residente com data de referência em 1 de julho de 2014 publicada no Diário Oficial da Região em 28/08/2014. Disponível em: http://cod.ibge.gov.br/234q2. Acesso em $16 / 08 / 2015$, às $11 \mathrm{~h} 40 \mathrm{~m}$.

JÁUREGUI, E.; TEJEDA, A. Urban-Rural Humidity Contrasts in Mexico City. International Journal of Climatology, v. 17, p.187-196, 1997.

JONSSON, P. Vegetation as an Urban Climate Control in the Subtropical City of Goborone, Botswana. International Journal of Climatology, v. 24, n.10 p.1307-1322, ago. 2004.

KUTTLER, W; WEBER, S; SCHONNEFELD, J; HESSELSCHWERDT, A. Urban/rural atmospheric water vapour pressure differences and urban moisture excess in Krefeld, Germany. International Journal of Climatology v. 27, n. 14 p. 2005-2015, nov. 2007.

LANDSBERG, H. E. O Clima das cidades. Revista do Departamento de Geografia, v. 18, p. 95-111, 2006.

LOMBARDO, M. A. Ilha de Calor nas Metrópoles: o exemplo de São Paulo. São Paulo: Editora Hucitec, 1985, 244 pgs.

MONTEIRO, C. A. F. A Climatologia Geográfica no Brasil e a Proposta de um Novo Paradigma. In MONTEIRO C.A.F. et al. (orgs) A Construção da Climatologia Geográfica no Brasil. Campinas: Editora Alínea, capitulo 2, p. 61-126, 2015.

MONTEIRO, C. A. F. e MENDONÇA, F. Clima Urbano. São Paulo: Contexto, 2003, 192 pgs.

MONTEIRO, C. A. F. Teoria e Clima Urbano. Tese [Livre-docência Geografia] Departamento de Geografia. São Paulo: IGEOG/USP; 1976. Série Teses e Monografias no. 25.

RIBEIRO SOBRAL, H. Heat island in São Paulo, Brazil: Effects on health. Critical Public Health, v. 15, n. 2 p. 147-156, jun. 2005.

RIBEIRO, H.; AZEVEDO, T. R. Meio Ambiente: Patrimônio Cultural da USP. O Patrimônio em áreas verdes da USP e a atmosfera urbana. São Paulo: EDUSP, (Cadernos CPC; 6) p. 19-40, 2003.

SILVA, A. L. SILVA, E. N. Análise Higrotérmico do Campo e da Cidade durante a Passagem de um Sistema Frontal no Período de Inverno em Sorocaba, SP. Revista Geonorte, Edição Especial 2, v.2, n.5 p. 123-134, 2012.

SILVA, E. N.; RIBEIRO, H.; SANTANA, P. Clima e Saúde em Contextos Urbanos: Uma Revisão da Literatura. Biblio 3W, Barcelona, v. XIX, n.1092 p.1-27, set. 2014. 
SILVA, E. N.; RIBEIRO, H. Ambiente Atmosférico do Setor Sudeste da Cidade de São Paulo. In IX Simpósio Brasileiro de Climatologia Geográfica. 2010, Fortaleza, Anais... Fortaleza: UFC 2010.

TAVARES, R. - O Clima Local de Sorocaba (SP) Tendências e Analise Comparativa Cidade- Campo. 1997. Dissertação (Mestrado em Geografia Física) Departamento de Geografia Faculdade de Filosofia, Letras e Ciências Humanas da Universidade de São Paulo, São Paulo, 1997. 